
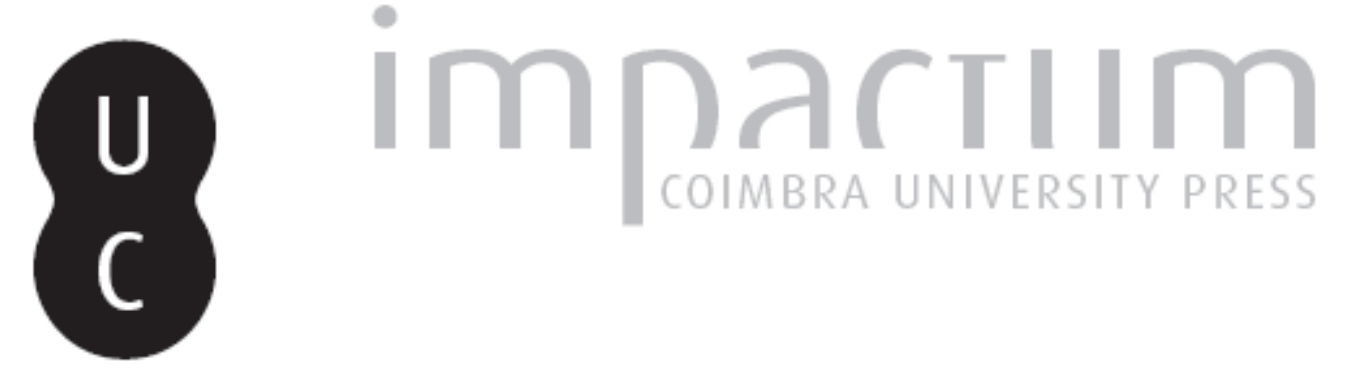

\title{
Margarita philosophica (1503): uma cyclopaedia do século XVI
}

\author{
Autor(es): $\quad$ Miranda, Margarida
}
Publicado por: Associação Portuguesa de Estudos Clássicos; Instituto de Estudos Clássicos

URL persistente:

URI:http://hdl.handle.net/10316.2/30437

DOI:

DOI:http://dx.doi.org/10.14195/0872-2110_50_7

Accessed : $\quad$ 26-Apr-2023 09:05:16

A navegação consulta e descarregamento dos títulos inseridos nas Bibliotecas Digitais UC Digitalis, UC Pombalina e UC Impactum, pressupõem a aceitação plena e sem reservas dos Termos e Condições de Uso destas Bibliotecas Digitais, disponíveis em https://digitalis.uc.pt/pt-pt/termos.

Conforme exposto nos referidos Termos e Condições de Uso, o descarregamento de títulos de acesso restrito requer uma licença válida de autorização devendo o utilizador aceder ao(s) documento(s) a partir de um endereço de IP da instituição detentora da supramencionada licença.

Ao utilizador é apenas permitido o descarregamento para uso pessoal, pelo que o emprego do(s) título(s) descarregado(s) para outro fim, designadamente comercial, carece de autorização do respetivo autor ou editor da obra.

Na medida em que todas as obras da UC Digitalis se encontram protegidas pelo Código do Direito de Autor e Direitos Conexos e demais legislação aplicável, toda a cópia, parcial ou total, deste documento, nos casos em que é legalmente admitida, deverá conter ou fazer-se acompanhar por este aviso.

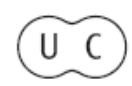




\section{Boletim de \\ Estudos Clássicos}

Associação Portuguesa de Estudos Clássicos Instituto de Estudos Clássicos

\section{Coimbra}

Dezembro de 2008 


\section{MARGARITA PHILOSOPHICA (1503) UMA CYCLOPAEDIA DO SÉCULO XVI}

Margarita philosophica (Pérola Filosófica) é o título de uma enciclopédia do início do século XVI, que reflecte o saber enciclopédico do seu tempo, o curriculum universitário de então e o estado do conhecimento científico dos finais do século XV e inícios do século XVI (1503).

$\mathrm{O}$ autor desta obra foi Gregor Reisch (1467-1525) mestre em Artes pela Universidade de Friburgo e depois monge da Ordem da Cartuxa e prior no Convento daquela cidade. Senhor de uma grande reputação como intelectual, Gregor Reisch relacionava-se com os maiores humanistas do seu tempo, entre eles Erasmo, e a sua obra-prima foi justamente a Margarita Philosophica, uma enciclopédia do conhecimento, concebida como livro de texto para estudantes.

Como num manual de catecismo, a exposição do texto segue o esquema de pergunta/resposta. $\mathrm{O}$ estudante coloca as questões e o mestre responde. Deste seu carácter didáctico resulta outra das particularidades da obra: a abundância de gravuras com que cada livro é ilustrado. Imagens de grande riqueza alegórica, outras de conteúdo estritamente técnico e descritivo, as xilogravuras da Margarita Philosophica têm suscitado diversos estudos sobre a sua autoria, mas todos eles inconclusivos. Nem assim diminuiu porém o interesse que elas têm suscitado junto dos leitores da obra. A verdade é que nem todos os exemplares chegaram completos aos nossos dias, e as páginas mutiladas são justamente as que correspondem às gravuras. Por mais rudimentares ou primitivas que sejam, as ilustrações da Margarita Philosophica são efectivamente um exemplo de quanto a imprensa podia desenvolver, não apenas a nível científico mas também a nível estético, os novos instrumentos de educação.

Logo que a imprensa permitiu a reprodução e circulação da informação, não foi apenas a informação textual mas também os suportes gráficos e visuais que foram colocados ao serviço da instrução literária e científica. Na Margarita Philosophica encontramos gravuras sobre gramática, anatomia, cosmografia, matemática, música, óptica e meteorologia, correspondentes a outros tantos livros que estruturam a obra. 
De grande utilidade didáctica seria também o índice de assuntos, ordenados por uma ordem alfabética (nem sempre rigorosa) no final da obra.

No início, sob a epígrafe Index librorum contentorum, um sumário apresenta a repartição da enciclopédia em 12 livros.

Os primeiros três livros correspondem ao triuium: I. Gramática Latina (prosa e poesia); II. Princípios de Dialéctica; III. Preceitos de Retórica.

Seguem-se as matérias do quadriuium: IIII. Aritmética (teórica e prática); V. Música (teórica e prática); VI. Elementos de Geometria (especulativa e prática); VII. Astronomia ("quer seja de natureza Matemática e Cosmográfica, quer seja a chamada Astrologia", acrescenta o texto).

Os livros seguintes correspondem à Filosofia Natural e à Filosofia Moral. À Filosofia Natural pertencem os livros VIII. Princípios da Filosofia Natural, sumariamente coligidos; IX. Origem dos seres naturais, simples e complexos; X. Alma vegetativa e alma sensitiva: diferenças; XI. A alma racional: origem, natureza e imortalidade; situação futura dos mortais. À Filosofia Moral pertence o último livro: XII. Filosofia Moral, "em que se faz o inventário das paixões, por ordem alfabética, para mais fácil consulta" acrescenta o autor, não sem remeter, porém, o leitor para o índice final da Margarita (Index eorum quae in appendicibus habent suo loco, post finem ipsius Margaritae).

O número de edições que a obra conheceu no século XVI é sinal do seu êxito. Aparentemente Gregor Reish teria um texto pronto a imprimir desde 1496, mas a edição sofreu algumas vicissitudes que fizeram com que o texto só viesse a ser finalmente publicado em 1503, em Friburgo, pelo impressor Johann Schott (mais conhecido como impressor de Estrasburgo). Logo no ano seguinte, o mesmo Johann Schott fez outra edição, desta vez em Estrasburgo, e outra ainda em 1508, em Basileia, em conjunto com Michael Furter, o qual, por sua vez apresentaria ainda mais duas edições, em 1517 e em 1519. Mas foi ainda em 1504 que teve início uma série de edições não autorizadas por Reisch, saídas da oficina de Johann Grüninger (Johannes Reinhard 1455-1533), em Estrasburgo. Em 1508, 1512 e 1515, Grüninger apresentou várias edições intituladas Margarita Philosophica Noua, que o monge da Cartuxa nunca autorizou. Nelas o impressor acrescentava outras matérias ao trabalho de Gregor Reisch (como os Architecturae et perspectivae rudimenta, de Martin Valdseemüler [1470-1521]). Em 1535 surge ainda outra edição, com introdução de emendas e de novos textos da autoria do matemático e cartógrafo francês Oronce Finé (1494-1555), a qual viria de novo à luz em 1583. Em 1599, seguir-se-lhe-iam traduções italianas a 
partir do texto francês de Oronce Finé. Em Friburgo, Estrasburgo, Basileia (por Heinric Petri), Paris e Veneza, as edições foram-se sucedendo até pelo menos 1600.

Graças à sua brevidade e graciosidade, a Margarita Philosophica tornou-se muito popular e veio a ser livro de texto em muitos Colégios e Universidades (especialmente na tradição alemã), tendo contribuído para a difusão do conhecimento, durante cerca de meio século.

Possui a Biblioteca Geral da Universidade de Coimbra cinco exemplares desta obra, uma das quais (R-33-10) de 1504, do impressor Johann Schott ou seja, a edição que a obra conheceu logo no ano seguinte ao da sua estreia ${ }^{1}$. As restantes são de 1517, 1535 e 1583.

Desde 1503 até ao fim do século XVI, pouco importava se o curriculum era mais medieval ou mais renascentista. O livro não se distingue pela introdução de conhecimentos novos, nem por alcançar todas as áreas de conhecimento, nem por oferecer um estudo exaustivo de uma determinada área do conhecimento em particular. O seu objectivo é simplesmente oferecer sínteses pedagógicas das principais áreas do saber que eram objecto de instrução de uma pessoa educada. ${ }^{2}$ Efectivamente, é à "juventude estudiosa" que Gregor Reisch dedica aquela obra.

Expressão de uma actualização humanística foi talvez o facto de a organização conceptual estritamente escolástica do conjunto desenvolver um interesse geral por tudo o que era venerado como antigo, observa Jens Høyrup, ${ }^{3}$ bem como o facto de incluir na sua organização dos saberes as "artes mechanicae (Lanificium, Armatura, Nauigatio, Agricultura, Venatio, Medicina e Theatrica)"como uma das duas partes da Philosophia Practica, designada como Philosophia Factiua, ao lado da Philosophia Actiua - que integrava, por sua vez a Ethica, Politica, Economica e Monastica.

Essa organização dos saberes mantinha, porém, intacta a estrutura das sete artes liberais que compunham o triuium e o quadriuium. $O$ triuium

${ }^{1}$ R-33-9, R-33-10, R-33-11, J.F.-60-4A-14 e 4A-27-16-22.

2 Richard Yeo - Encyclopaedic visions: scientific dictionaries and enlightment culture. Cambridge University Press, 2001. Foi, aliás, em matéria científica que o livro suscitou maior interesse da parte dos leitores e dos historiadores, principalmente como livro de matemática. Cf. Jens Høyrup - Measure, Number, and Weight. Studies in Mathematics and Culture, State University of New York Press, Suny Press, 1994.

${ }^{3}$ Measure, Number and weight..., 1994, p. 159. 
aparecia como uma das partes da Philosophia Theorica siue speculatiua, correspondente à Philosophia Theorica Rationalis (Grammatica, Rhetorica et Logica); o quadriuium correspondia às quatro partes da Mathematica (Arithmetica, Geometria, Musica e Astronomia), integrando, juntamente com a Metaphysica e a Physica, as três partes da Philosophia Theorica Realis. Assim, na Philosophiae Partitio de Gregor Reish, a Philosophia dividia-se em Teórica e Prática. A Teórica podia ser Racional ou Real. Se a Filosofia Racional correspondia ao triuium, a Filosofia Real repartia-se em Física (ou seja, a chamada Filosofia Natural "incluindo a medicina teórica"), Matemática (que correspondia ao quadriuium) e Metaphísica, que segundo o autor incluía a Teologia e Sagrada Escritura). A Filosofia Prática incluía, como acima se disse, a Filosofia Activa e a Factiva.

Não se confunda, no entanto, a Philosophiae Partitio de Gregor Reisch tal como o autor a apresenta na sua Margarita Philosophica, com a estrutura interna da pequena enciclopédia em doze livros: três para o triuium, quatro para o quadriuium, quatro para a filosofia natural e um apenas para a filosofia moral. Nem nos espante que a Filosofia Natural de Reisch inclua os elementos, a meteorologia, o reino das plantas e dos animais juntamente com a óptica, a astrologia e a alquimia, a memória, o céu, o inferno e o purgatório.

Entre as gravuras mais interessantes da Margarita Philosophica salienta-se a da folha de rosto que reassume o conteúdo do livro, ou seja o ciclo (ou círculo) das artes e das ciências (fig. 1).

$\mathrm{O}$ ciclo das artes e das ciências é identificado com a seguinte legenda: PHILOSOPHIA TRICEPS NATVRALIS, RATIONALIS, MORALIS. Dentro do círculo encontra-se uma figura feminina coroada - a Filosofia - com um ceptro na mão. As três cabeças da Filosofia representam a tripartição anunciada na legenda (Filosofia Natural, Racional e Moral). No centro do seu vestido está desenhada a escada do conhecimento, que conduz da Philosophia Practica à Philosophia Theorica (representada pela letra T, ao cimo da escada e do vestido).

À volta da Filosofia dispõem-se outras sete mulheres, as sete artes liberais, identificadas pelos seus atributos tradicionais. Ao centro, a Aritmética, sentada aos pés da Filosofia, com o ábaco sobre o regaço. À direita, a Música com a harpa na mão, a Geometria com o compasso, e a Astronomia, com o globo terrestre. À esquerda, a Lógica, a Retórica (com um rolo) e a Gramática. 
Por cima do círculo vemos os quatro primeiros doutores da Igreja, Santo Agostinho, São Gregório, S. Jerónimo e Santo Ambrósio 4 . Todos eles apontam para a bandeira da Philosophia Diuina, nas mãos de São Gregório.

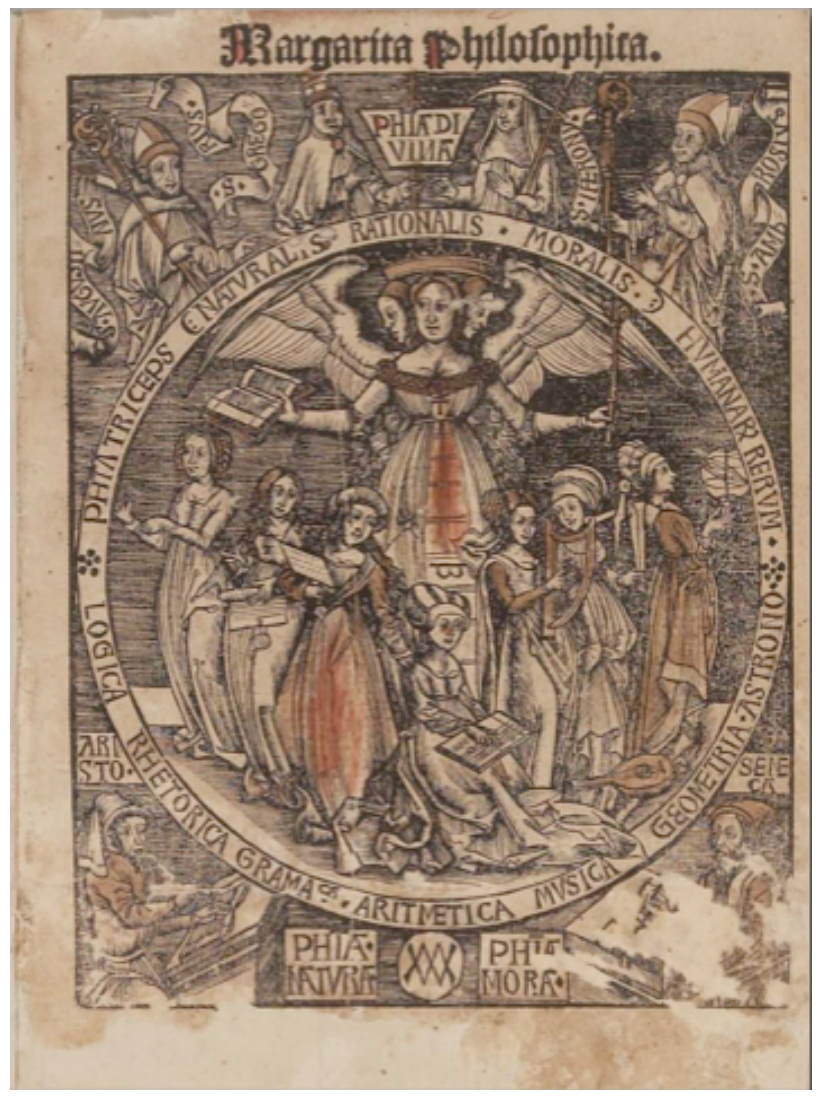

Fig. 1 - Gregor Reisch, Margarita Philosophica. Basileia, 1504. Folha de Rosto. B.G.U.C. R-33-10.

4 Ou seja, os doutores latinos. Os doutores gregos (São João Crisóstmo, São Basílio de Cesareia, São Gregório Nazianzeno e Santo Atanásio de Alexandria) só foram proclamados Doutores da Igreja em 1568 e o próprio São Tomás de Aquino, cuja presença esperaríamos, só o foi em 1567, pelo Papa Pio V. 
Na parte inferior, à esquerda vemos Aristóteles, ícone da Philosophia Naturalis, e à esquerda Séneca, ícone da Philosophia Moralis.

Embora a obra não se intitule Enciclopédia, um dos epigramas incluídos nas páginas finais refere-se-lhe como cyclop[a]edia. Esse parecia ser o modo como Gregor Reisch concebia a sua obra, ao menos à luz da gravura inicial: o ciclo ou círculo integral das artes e das ciências.

O termo enkyklopaideia não se encontra em autores gregos. É dado por Quintiliano (Inst. I. 10) e por Plínio o Antigo (Hist. Nat. Pref.) Os autores gregos utilizavam a expressão enkyklios paideia para designar «a educação que abrange o ciclo integral» ou «o conjunto das disciplinas que dão uma educação completa». Este significado originário de Enciclopédia tendeu a desaparecer, mas parece ser o que está subjacente ao autor da gravura que dá rosto à Margarita Philosophica, ou Pérola Filosófica.

Também o livro se estrutura como uma enciclopédia, ou seja, uma exposição sistemática (também alfabética) de um conjunto amplo de disciplinas, em que sobressaem as sete artes liberais, junto da Filosofia Natural, a Filosofia Moral e a Filosofia Divina, no cimo de todas.

\section{Outras leituras:}

Robert Collison - Encyclopaedias: their history throughout the ages. A bibliographical guide with extensive historical notes to the general encyclopaedias issued throughout the world from 350 B.C. to the present day. New York, London 1966;

Udo Becker - Die Erfte Enzyklopädie aus Freiburg um 1495: Die Bilder der Margarita Philosophica des Gregorius Reisch, Prior de Kartause. Freiburg, Herder, 1970;

Lutz Geldsetzer (Ed.) - Margarita philosophica. Mit einem Vorwort, einer Einleitung und einem neuen Inhaltsverzeichnis von Lutz Geldsetzer. Düsseldorf, 1973;

Lucia Andreini (Ed.) - Gregorius Reisch: Margarita philosophica nova. 3 tomi. Introducione di Lucia Andreini. Nachdruck der GrüningerAusgabe von 1508 mit einem Einleitungsband; Institut für Anglistik und Amerikanistik der Universität Salzburg. Salzburg, 2002;

Frank Büttner - «Die Illustrationen der Margarita Philosophica des Gregor Reisch» in Frank Büttner, Markus Friedrich, Helmut Zedelmaier (Eds.): Sammeln-Ordnen-Veranschaulichen. Zur Wissenskompilatorik in der Frühen Neuzeit. Münster 2003, pp. 269-300; 
Hans Georg Wehrens - «Gregor Reisch, seine Margarita philosophica und Freiburg im Breisgau» in Zeitschrift des Breisgau-Geschichtsvereins Schau-ins-Land, Freiburg, 2004, pp. 37-57;

A.A.V.V. - O livro científico dos séculos XV e XVI: ciências físicomatemáticas na Biblioteca Nacional, Biblioteca Nacional, 2004, maxime Henrique Leitão «O livro científico antigo, séculos $\mathrm{XV}$ e XVI. Notas sobre a situação portuguesa», pp. 15-35.

MARGARIDA MIRANDA 